\title{
Residual Level of Phosphorus and Potassium Nutrients in Hydroponically Grown Cotton (Gossypium hirsutum)
}

\author{
Adebusoye O.Onanuga (Corresponding author) \\ Department of Biology, Dalhousie University, 1355 Oxford Street, Halifax, Nova Scotia, B3H 4J2. Canada \\ Tel: 1-902-494-2753,902-404-9452Ｅ-mail: Adebusoye.Onanuga@Dal.Ca \\ Ping'an Jiang \\ College of Natural Resources and Environmental Sciences, Xinjiang Agricultural University \\ No 42 Nanchang Road, Urumqi 830052, China \\ Tel: 86-130-779-998-656_E-mail: jiang863863@sina.com
}

Sina Adl

Department of Biology, Dalhousie University, 1355 Oxford Street

Halifax, Nova Scotia, B3H 4J2, Canada

Tel: 1-902-494-2753 E-mail: sadl@Dal.Ca

Received: December 15, 2011

Accepted: January 6, $2012 \quad$ Online Published: April 1, 2012

doi: $10.5539 /$ jas.v4n5p149

URL: http://dx.doi.org/10.5539/jas.v4n5p149

\begin{abstract}
Sustainable agriculture requires economical and judicious use of mineral fertilizers and other farm inputs such as synthetic plant hormones so as to benefit crop growth, development and yield. The present study investigated residual levels of phosphorus $(\mathrm{P})$, potassium $(\mathrm{K})$ nutrients and nutrient solution level in the hydroponics by application of low $\mathrm{P}$, low $\mathrm{K}$ and high PK nutrients to hydroponics pots in the first experiment, and by spraying cotton plants with indole -3- acetic acid (IAA), gibberellic acid $\left(\mathrm{GA}_{3}\right)$, zeatin $(\mathrm{Z})$ and their combinations at high level of PK nutrient in the second experiment. In the first experiment, nutrient solution level in the hydroponics irrespective of varieties of cotton planted in them and those with specific cotton varieties were significantly affected by the treatments. However, low P, low K and high PK treatments irrespective of the two cotton varieties planted in the hydroponics pots significantly influenced residual level of $\mathrm{P}$ and $\mathrm{K}$ nutrients. During the second experiment, the exogenous hormones applied irrespective of two cotton varieties planted in the hydroponics pots did not affect nutrient solution level in the hydroponics except at 43 and 80 days after transplanting (DAT). Nevertheless, taken the two cotton varieties into consideration, Zhong cotton variety had higher nutrients solution level than Xin cotton variety. In general, hormones applied did not affect residual P and $\mathrm{K}$ in the nutrients solution after every nutrients change except at 43 DAT. However, varietal differences were observed for high residual $\mathrm{P}$ and $\mathrm{K}$ nutrients at 80 and 90 DAT for $\mathrm{P}$ and 74 and 90 DAT for $\mathrm{K}$ in the nutrient solution grown with Xin cotton variety. It is clear from these results that wise usage of mineral fertilizers and synthetic plant hormones should be taken into consideration in order to avoid wastage.
\end{abstract}

Keyword: Residual phosphosrus, Potassium, Indoacetic acid, Gibberellic acid, Zeatin, Hydroponics

\section{Introduction}

Environmental degradation occurs as a result of over use of chemical fertilizer leading to environmental pollution through excess chemical nutrients solution left behind after cropping in the hydroponics systems. Chemical fertilizer must be used in appropriate quantities to mitigate environmental impact and reduce production cost. The absorption of water and mineral nutrients depend on the early growth of cotton roots (Oosterhuis and Zhao, 1994), but there are some occasions whereby high levels of phosphorus and potassium are left behind in excess after cropping in hydroponics systems. However under some circumstances, residual nutrients in soils or hydroponics may provide a nutrient resource for cropping in subsequent cropping seasons. 
Previous studies have indicated that residual P-nutrient had a greater effect on foliar, forest floor and soil nutrient content than K-residual level (Crous, et al., 2008).

Furthermore, Benbi and Biswas, (1999) reported that residual levels of $\mathrm{P}$ in the soil depends on rate and the total amount of P added and its removal by the crops. Obigbesan and Akinrinde, (2000) confirmed the beneficial effect of residual $\mathrm{P}$ (rock phosphate source) on millet height and biomass planted in strongly acidic soils. Akinrinde et al., (2003) stated that residual P (single super phosphate fertilizer source) had favourable effect of releasing unused $\mathrm{P}$ to the crop during the subsequent planting.

Plant growth, development and yield depend on adequate water and nutrients (nutrient solution) supply to the crop, especially during the seedling and reproductive stages. An investigation made by Kozlowski, (1972) and Stevenson, (1982) reported that water and plant nutrients are the most important variables for producing profitable yield. Plant hormones can also be used to stimulate water and nutrient use efficiency. Duli Zhao and Derrick Oosterhuis, (1997) concluded that PGR IV (combination of Gibberellic acid and auxin) has the ability to partially remove detrimental effect of water stress on biomass accumulation and photosynthesis in order to improve the growth and nutrients absorption of cotton. The present study investigated the residual level of phosphorus and potassium after growing of two cotton varieties in a hydroponics system. The main objectives of this research effort were: to investigate the residual level of $\mathrm{P}$ and $\mathrm{K}$ nutrient in a hydroponic solution used for the cultivation of cotton. In addition, the effect of exogenous hormones application on residual level of $\mathrm{P}$ and $\mathrm{K}$ nutrients cultivated with cotton grown in hydroponic nutrient solution was examined. Differences between the residual levels of $\mathrm{P}$ and $\mathrm{K}$ related to hormone and no hormone treatment were evaluated.

\section{Materials and Methods}

\subsection{Experiment 1}

The two Chinese cotton varieties (Zhong and Xin cotton) were cultivated in quartz sand. The cotton seedlings were transplanted into a $6 \mathrm{~L}$ pot at seven days of planting containing a hydroponic nutrient solution. These specifications were followed: The day time temperature was kept at $20-35^{\circ} \mathrm{C}$, this temperature range was achieved by covering the greenhouse with black blanket to conserve heat. The surrounding sunlight was maintained above 12 hours using the electrical lighting, there was a constant supply of oxygen to the cotton roots provided through aeration pumps. The nutrients solutions used were based on a standardized Hoagland solution modified with the required micro-anion nutrients. The treatments levels were $5.0 \times 10^{-5} \mathrm{M}$ for low $\mathrm{P}, 10^{-3} \mathrm{M}$ for low $\mathrm{K}, 10^{-3}$ and $6 \times 10^{-3} \mathrm{M}$ for high PK. (Table 1) at $\mathrm{pH} 6.5$ with the two varieties of cotton grown in the hydroponics. The nutrient solution level in the hydroponics containers was measured with graduated ruler at 21, 46, 57 and 72 days after transplanting. Phosphorus and potassium contents in the solution in each pot were measured using standard laboratory techniques developed by Olsen and Sommer, (1982) for phosphorus and Richards, (1954) for potassium. The three treatments (low P, low K and High PK) were replicated fifteen times in each of the two cotton varieties grown in the pots resulting to 90 experimental pots $(3 \times 15 \times 2)$. At day 83,91 , 104, 120 and 148 after transplanting, three pots were randomly selected for each of the two cotton varieties from each treatment replicated three times $3 \times 3 \times 2$ resulting to 18 experimental pots to measure nutrient solution level in the hydroponics pots using graduated ruler and $\mathrm{P}$ and $\mathrm{K}$ in the hydroponics using Olsen and Sommer, (1982) for phosphorus and Richards, (1954) for potassium at each time interval.

\subsection{Experiment 2}

The exogenous hormones concentration were applied twice at day 36 and 67 after transplanting by spraying on the cotton leaves at single rate of $0,50,40$ and $50 \mu \mathrm{g} \mathrm{L}^{-1}$ for control, indole -3- acetic acid (IAA), gibberellic acid $\left(\mathrm{GA}_{3}\right)$ and zeatin $(\mathrm{Z})$, respectively and in combined rates of 50IAA x 40GA x 50Z, 100IAA x 40GA x 50Z, 50IAA x 80GA x 50Z, 50IAA x 40GA x 100Z and 100IAA x 80GA x 100Z. Hormones used in this experiment especially zeatin needed in small quantity which influenced plant growth and development. At day 43 and 74 after transplanting, nutrient solution level in the hydroponics pots was measured with graduated ruler, phosphorus and potassium contents were measured in the hydroponics using method described in experiment 1 . The eight hormone treatments and control were replicated six times for each of the two cotton varieties $(9 \times 6 \times 2)$ resulting to 108 experimental hydroponics pots. At day 80 and 90 after transplanting, randomly selection of nine hormones treated pots including control were replicated three times grown with two cotton varieties, resulting to a total number of 54 pots $(9 \times 3 \times 2)$ in each period of parameters measurement.. The hydroponics nutrient solution was supplied with the high PK nutrients level of $10^{-3} \mathrm{M}$ and $6 \times 10^{-3} \mathrm{M}$ (Table 1) at pH 6.5 and all other cultivation and growth conditions were maintained as in Experiment 1. 


\subsection{Data Analysis}

The data generated were subjected to analysis of variance (ANOVA) using general linear model (GLM) with SPSS software. Least significant differences using Duncan's multiple range test (DMRT) for separation of treatment irrespective of the two varieties and variety means was applied to the data. Pearson's correlation statistical analysis was used to compare nutrient solution level and $\mathrm{P}$ and $\mathrm{K}$ nutrients content in the hydroponics system for both experiments.

\section{Results}

3.1 Nutrient solution level and residual level of $P$ and $K$ contents in a hydroponic system used for cultivating two cotton varieties treated with Low $P$, Low K and High PK

Nutrient solution level of hydroponically grown cotton plants is shown in Table 2. The nutrient solution level in the hydroponics pot treated with low $\mathrm{P}$ was consistently higher than low $\mathrm{K}$ and high PK treatments from 21 to 148 DAT. The plants grown in the low K and high PK treatments were the same level at 21, 46, 57, 83 and 148 DAT while the high PK treatment had lower nutrient solution level than the low P and low K treatments at 72 , 91,104 and 120 DAT.

It is clear from Table 3 that there was no significant difference in residual $\mathrm{P}$ content in the nutrient solutions from the low P, low K and high PK treatments at 21 DAT. However, the low K treatment had a higher residual P content than the low P and high PK treatments with concentrations of 14.67, 14.53, 16.40, 11.72, 12.15, 12.97, 11.21 and $15.48 \mathrm{mg} \mathrm{pot}^{-1}$ at 46, 57, 72, 83, 91, 104, 120 and 148 DAT, respectively. In contrast, the low P treatment had the lowest residual P content with concentrations of $0.863,1.49,0.396,0.449,0.765,0.563,0.705$ and $0.458 \mathrm{mg} \mathrm{pot}^{-1}$ at 46, 57, 72, 83, 91, 104, 120 and 148 DAT, respectively. Low P and high PK treatments were not significantly different at 46 DAT.

Table 4 shows that low P treatment produced the highest residual K content (291.52 $\mathrm{mg} \mathrm{pot}^{-1}$ ) than either the high PK treatment (261.77 $\left.\mathrm{mg} \mathrm{pot}^{-1}\right)$ or the low K treatment $\left(37.37 \mathrm{mg} \mathrm{pot}^{-1}\right)$ in the hydroponics nutrient solution at 21 DAT. In contrast, the high PK treatment had the highest concentrations of residual $\mathrm{K}$ than the other two treatments with values of $283.91,249.82,304.38,313.88,323.99,338.81,339.22$ and $302.50 \mathrm{mg} \mathrm{pot}^{-1}$ from 46 to 148 DAT, respectively. The low $\mathrm{K}$ treatment responded with lower concentrations of residual K with values of $29.49,38.27,32.46,35.39,39.68,40.11,45.61$ and $47.49 \mathrm{mg} \mathrm{pot}^{-1}$ from 46 to 148 DAT.

3.1.1 Differences between the two cotton varieties in relation to nutrient solution level and $\mathrm{P}$ and $\mathrm{K}$ residual levels in the hydroponics

Figure 1 shows the two varieties exhibiting irregular downward movement from highest level to lowest level of nutrients solution from 21 to 120 DAT with upward movement beyond 120 DAT. Xin Cotton variety proved superior to Zhong cotton variety by having higher level except at 83 and 120 DAT which showed no significant difference between the two varieties.

Figure 2 reveals that there was a steady increase in $\mathrm{P}$ concentration in the nutrient solution in the early growth stage, with small or decreased concentrations during the reproduction stage. Xin cotton and Zhong cotton varieties displayed no differences in residual phosphorus content in the hydroponics nutrient solution treatments.

Figure 3 shows a gradual two times decrease of K content (from 198.94 to $194.95 \mathrm{mg} \mathrm{pot}^{-1}$ ) from 21 to 46 DAT (early growth stage) and a sharp decrease beyond 46 to 57 DAT in K content of 194.95 to $167.32 \mathrm{mg} \mathrm{pot}^{-1}$ in the hydroponics nutrient solution, a gradual increase as from 57 to 120 DAT, then a decrease thereafter. The two cotton varieties were not significantly different from each other in regards to residual $\mathrm{K}$ content in the hydroponics nutrient solution.

\subsection{Effect of hormone treatments on nutrient solution level and residual level of $P$ and $K$ in the hydroponically grown cotton}

The effects of hormone treatments on nutrient solution level at the high rates of $\mathrm{P}$ and $\mathrm{K}$ nutrients with hydroponically grown cotton are presented in Table 5. There was no significant difference between treated hydroponic pots and untreated hydroponic pots at 74 and 90 DAT. It is noteworthy that at 43 DAT the IAA x GA $\mathrm{x} \mathrm{Z}$ treatment had significantly lower nutrient solution level than all other treatments, including the control pot. However, at 80 DAT, IAA $\times \mathrm{GA}_{3} \times \mathrm{Z}, 2 \mathrm{IAA} \times \mathrm{GA}_{3} \times \mathrm{Z}$ and IAA $\times 2 \mathrm{GA}_{3} \times \mathrm{Z}$ treatments had significantly greater levels of nutrient solution than the other treatments.

Table 6 shows that untreated hydroponic pot $\left(1.35 \mathrm{mg} \mathrm{pot}^{-1}\right)$ gave significantly higher residual phosphorus concentrations than treated pots, but there were no differences between untreated hydroponic pot and those of single hormone treated pots (IAA, $\mathrm{GA}_{3}, \mathrm{Z}$ ) or combined hormone treated pots (2IAA x $\mathrm{GA}_{3} \times \mathrm{Z}$, IAA $\times 2 \mathrm{GA}_{3} \times \mathrm{Z}$, 
IAA $\times \mathrm{GA}_{3} \times 2 \mathrm{Z}$ and $\left.2 \mathrm{IAA} \times 2 \mathrm{GA}_{3} \times 2 \mathrm{Z}\right)$. The IAA $\times \mathrm{GA}_{3} \times \mathrm{Z}$ treated pot $\left(1.11 \mathrm{mg}^{-1}\right.$ pot $\left.^{-1}\right)$ gave the lowest residual $\mathrm{P}$ concentration at 43 DAT. Conversely, from 74 to 90 DAT, treated pots and untreated pots were not significantly different in residual phosphorus content

It is clearly seen from Table 7 that IAA $x \mathrm{GA}_{3} \times \mathrm{Z}$ treated pots had significantly higher residual K-content than all other treatments at 43 DAT. Nevertheless, from 74 to 90 DAT, there were no significant differences between any of the treatments.

3.2.1 Differences between the two cotton varieties in relation to nutrient solution level and residual level of $\mathrm{P}$ and $\mathrm{K}$ in the hydroponics treated to different hormones

A decrease in nutrient solutions level was observed from 43 to 74 DAT, with a sharp increase from 74 to 80 DAT and another decrease from 80 to 90 DAT. The Zhong cotton variety was superior to Xin cotton variety in nutrient solution level in the hydroponics throughout the experimental period (Fig 4).

Figure 5 shows that $\mathrm{P}$ remaining in the nutrients solution decreased from 43 to 74 DAT, with a sharp increase from 74 to 80 DAT and a decrease thereafter. Xin and Zhong cotton varieties were not significantly different at 43 and 74 DAT as regards residual P content in the hydroponics nutrient solution. However, from 80 to 90 DAT, Xin cotton plants grown in hydroponics nutrients solution had higher residual P content than Zhong cotton.

Figure 6 reveals that there was a gradual increase in residual K content from 43 to 74 DAT, a decrease at 80 DAT and a sharp increase at 90 DAT. There were no significant differences for the two varieties at 43 and 80 DAT in relation to residual $\mathrm{K}$ content. However, there were drastic changes for the two varieties at 74 and 90 DAT in the hydroponics nutrient solution; Xin cotton variety that was planted in the nutrient solution had more residual $\mathrm{K}$ content than Zhong cotton variety.

3.3 Correlation co-efficient relating low P, low K and high PK treated plants at 148 DAT to hormones treated plants at high level of PK at 90 DAT

The correlation co-efficients relating the first and second experiments are given in Table 8. The correlation between first and second experiment in relation to nutrient solution level in the hydroponics and $\mathrm{P}$ and $\mathrm{K}$ residual levels after every nutrients change were not statistically significant $(r=-0.981,0.951,0.973)$.

\section{Discussion}

4.1 Nutrient solution level and residual levels of Phosphorus and Potassium of hydroponically grown cotton varieties

The results of the study illustrate the effectiveness of cotton plants to utilize the nutrient solutions (such as phosphorus and potassium nutrients) in the hydroponics system during growth and development stages of these varieties (Kozlowski, 1972; Stevenson, 1982). Xin cotton variety had greater level of nutrient solution in the hydroponics than the Zhong cotton variety. This implies that Zhong cotton variety absorbed more nutrients than Xin cotton plants. The acquisition of $\mathrm{P}$ by cotton plants was noticed at the reproductive stage while $\mathrm{K}$ absorption was noticed at early growth stage. The residual levels of $\mathrm{P}$ and $\mathrm{K}$ at every sampling period showed that the low $\mathrm{K}$ treated plants gave higher residual P concentrations while low $\mathrm{P}$ treated pot gave the least. On the other hand, residual K content in the high PK treated pots had the higher residual K while low K treated pot had the lowest. This suggests that an increase in nutrient levels where they are not limiting can lead to wasted fertilizer in remaining in solution (Hallmark and Barber, 1984). Asher and Ozanne (1967) noticed that an increase in K in the nutrient solution increased the $\mathrm{K}$ content and yield of both the shoots and roots of several pasture crop species. Furthermore, frequent addition of nutrients to the soil or in hydroponic systems can result in high residual level of nutrients in solution. This may provide ample available nutrients or its level may be toxic to the crops. Conversely, phosphorus decrease in the nutrients solution at the reproduction stage implies that high content of $\mathrm{P}$ is required at this period (Hallmark and Barber, 1984, José et al 2002), although both cotton varieties planted in hydroponics were not significantly different in residual levels of phosphorus and potassium.

4.2 Nutrient solution level and residual level of phosphorus and potassium of hydroponically grown cotton varieties treated to different hormones

Hormone treated pots were significantly affected by the nutrient solution level in the hydroponics system. It became obvious at 43 DAT that hormone treated pots with IAA $\times \mathrm{GA}_{3} \times \mathrm{Z}$ had lower level of the nutrient solution. This implies that cotton plants were utilizing nutrients more efficiently through the influence of the added hormones (José et al 2002). However, results obtained at 80 days after transplanting showed an opposite trend in all hydroponic pots treated with hormones and untreated pot except for the IAA x GA $\times$ Z, 2IAA x GA $x \mathrm{Z}$ and IAA $\times 2 \mathrm{GA}_{3} \times \mathrm{Z}$ treatments. This could be due to higher level of hormone concentrations added at day 
67 after transplanting which altered cotton growth and development. Different genetic constitutions of the two varieties suggest better performance of Zhong cotton variety over Xin cotton variety (Jiang, et al., 2008).

Exogenous application of hormones did not affect $\mathrm{P}$ and $\mathrm{K}$ mineral nutrients in the hydroponics nutrient solution, it might also be due to higher level of hormones application at 67 DAT, as a result of this, treated pots and untreated pots statistically appeared the same except at $43 \mathrm{DAT}$, where combined use of IAA $\times \mathrm{GA}_{3} \times \mathrm{Z}$ gave significantly lower $\mathrm{P}$ content in the nutrients solution. This treatment was not significantly different to other treatments except for the control treatments. The low $\mathrm{P}$ content in the hydroponics nutrient solution could be due to effective $P$ acquisition by plants.

There was a decrease in P level from 43 to 74 DAT and sharp rise at 80 DAT, finally decrease at 90 DAT (Fig 4). This signifies that hormones alter cotton plant growth whereby high $\mathrm{P}$ content is needed during seedling up to reproductive stage (José, et al., 2002). Xin cotton performed better than Zhong cotton in nutrients absorption capacity at 80 and 90 DAT due to their genetic variations (Jiang, et al., 2008). On the contrary, the pot treated with IAA $\times \mathrm{GA}_{3} \times \mathrm{Z}$ had significantly higher residual K-content in the nutrients solution at 43 days after transplanting. This implies that this treatment influenced K-content to remain in the solution at 43 DAT whereas other treatments including untreated plants caused effective $\mathrm{K}$ utilization by the cotton plants. The IAA $x \mathrm{GA}_{3} \times \mathrm{Z}$ exogenous hormone treatment plays two conflicting roles. It helps in P-utilization on one hand and on the other hand, high K-content was left unused in the nutrients solution. This result could also be attributed to the higher concentration of $\mathrm{K}$ in the hydroponics nutrient solution (Table 1). Furthermore, hormone treatments did not influence residual $\mathrm{P}$ and $\mathrm{K}$ from 74 to 90 days after transplanting could be due to higher concentration of hormone added at 67 DAT. Shah et al (2006) reported that highest growth, NPK accumulation and seed yield of Black Cumin (Nigella sative L) was obtained when $\mathrm{GA}_{3}$ is sprayed at 40 days after sowing (DAS). However, high K content was utilized by the two varieties from 74 to 80 DAT during the reproductive stage. Zhiyong et al, 2009 confirmed that high $\mathrm{K}$ nutrient is needed for cotton growth and yield. Xin cotton performed better than Zhong cotton in nutrient absorption capacity at 74 and 90 DAT due to their genetic variations of the two varieties. (Jiang, et al., 2008).

\subsection{The relationship between first cropping and second experiments.}

Pearson's correlation was not statistically significant for nutrient solution level in the hydroponics and residual level of phosphorus and potassium at different harvesting time (148 and 90 DAT for first and second experiments, respectively) when comparing the first and second experiment. This could be due to the fact that plant hormones influenced the nutrients acquisition and transportation at the early growth stages which facilitated more rapid growth and development than those without exogenous hormone application (Nickell, 1982).

\section{Conclusions}

The results of this investigation suggest the economical use of nutrients and synthetic hormones to support growth and development of cotton. Nutrient concentrations applied in this study indicated that low K and High PK treatments had high residual $\mathrm{P}$ and $\mathrm{K}$ nutrients content in the hydroponics nutrient solution. This contributes to $\mathrm{P}$ and $\mathrm{K}$ wastage that could lead to environmental degradation. The application of hormones did not change $\mathrm{P}$ and $\mathrm{K}$ residual level in the nutrients solution except at early growth stages for both nutrients (43 DAT).This advocates for economical use of synthetic hormones, excessive hormones application can jeopardize nutrients acquisition by cotton plants. Xin cotton variety influenced more residual $\mathrm{P}$ and $\mathrm{K}$ in the nutrients solution than Zhong cotton variety. This suggests that Zhong cotton variety absorb more nutrients than Xin variety. Therefore, judicious use of nutrients fertilizer and plant hormones should be given priority consideration in hydroponics with regards to cotton varieties.

\section{References}

Akinrinde, E.A., Onanuga, O.A., Bello, O.S. \& Obigbesan, G.O. (2003). Efficiency of indigenous ground phosphate rocks, organic fertilizer and their mixtures for maize performance in two Nigerian alfisols. Moor Journal of Agricultural Research, Vol. 4, 1-4.

Asher, C. J., \& P. G. Ozanne. (1967). Growth and potassium content of plants in solution cultures maintained at constant potassium concentrations. Soil Science, 103, 155-161.

Benbi D. K \& Biswas, C. R. (1999). Nutrient budgeting for phosphorus and potassium in a long-term fertilizer trial. Nutrient Cycling in Agroecosystems, 54, 125-132. http://dx.doi.org/10.1023/A: 1009720103190

Chapman, H. D., \& P. F. Pratt. (1961). Methods of analysis for soils, plants and water Univ of California, Berkeley, CA U.S.A. 
Crous, J. W., Morris A. R. \& M. C Scholes. (2008). Growth and foliar nutrient response to recent applications of phosphorus $(\mathrm{P})$ and potassium $(\mathrm{K})$ and to residual $\mathrm{P}$ and $\mathrm{K}$ fertilizer applied to the previous rotation of Pinus patula at Usutu, Swaziland. Forest Ecology and Management, 256 pp 712-721. http.://dx.doi.org/10.1016/j.foreco.2008.05.024

Hallmark W. B \& S. A. Barber. (1984). Root growth and morphology, nutrient uptake and nutrient status of early growth of soybeans as affected by soil P and K. Agronomy J., 76, 209-212.

Jiang Cun-cang, Chen Fang, Gao Xiang-Zhao, Lu Jian-wei, Wan Kai-yuan, Nian Fu-Zhao \& Wang Yun-hua (2008). Study on the nutrition characteristics of different K use efficiency cotton genotypes to K deficiency stress. Agricultural Sciences in China, 7(6), 740-745. http://dx.doi.org/10.1016/S1671-2927(08)60109-1

José López-Bucio, Esmeralda Hernandez-Abreu, Lenin Sanchez-Calderon, Maria Fernanda Nieto-Jacobo, June Simpson \& Luis Herrera-Estrella. (2002). Phosphate availability alters architecture and causes changes in hormones sensitivity in the Arabidopsis root system. Plant Physiology, Vol. 129, pp 244-256. http://dx.doi.org/10.1104/pp.010934

Kozlowski, T.T. (Ed.). (1972). Water Deficits and Plant Growth. Academic Press, New York.

Nickell, L.G. (1982). Plant Growth Regulators: Agricultural Uses, Springer, New York, p. 173.

Obigbesan, G. O \& Akinrinde, E. A. (2000). Evaluation of the performance of Nigerian rock phosphates applied to millet in selected Benchmark soils. Nigerian Journal of Soil Sci., 12, 88-99.

Olsen, S. R \& L. E Sommers. (1982). Phosphorus. pg 403 - 430. In A.L. Page (ed.). Method of soil analysis, Agron, No.9, Part 2. Chemical and microbiological properties, $2^{\text {nd }}$ ed., Am. Soc. Agron., Madison, WI USA.

Oosterhuis, D. M \& Zhao, D. (1994). Increased root length and branching in root by soil application of the plant growth regulator PGR-IV. Plant and soil, 167, 51-56. http://dx.doi.org/10.1007/BF01587597

Richards, L. A. (1954). Diagnosis and improvement of saline and alkaline soils. USDA Agric. handbook 60 Washington, D.C.

Shah, S. H, Ahmad, I \& Samiullah. (2006). Effect of gibberellic acid spray on growth,nutrient uptake and yield attributes during various growth stages of Black cumin ( Nigella sativa L.). Asian Journal of Plant Sciences, 5(5), 881-884. http://dx.doi.org/10.3923/ajps.2006.881.884

Stevenson, F. J. (1982). Nitrogen in agricultural soils. Agron Monogr. 22 ASA, CSSA and SSSA. Madison, WI.

Zhao Duli \& Derrick Oosterhuis. (1997). Physiological response of growth chamber-grown cotton plants to the plant growth regulator PGR-IV under water-deficit stress .Environmental and Experimental Botany, Vol. 38 (1) pp7-14. http://dx.doi.org/10.1016/S0098-8472(97)00002-6

Zhiyong Zhang, Fuqiang Yang, Bo Li, Egrinya Eneji A, Jianmin Li, Liusheng Duan,Baomin Wang, Zhaohu Li \& Xiaoli Tian. (2009). Coronatine-induced lateral-root formation in cotton (Gossypium hirsutum ) seedlings under potassium-sufficient and deficient conditions in relation to auxin. J. Plant Nutri. Soil Sci., 172, 435-444. http://dx.doi.org/10:1002/jpln.200800116

Table 1. Hydroponics nutrient composition

\begin{tabular}{|c|c|c|c|c|}
\hline Nutrients & $\begin{array}{l}P \\
1 \times 10^{-3}\end{array}$ & $\begin{array}{l}P \\
\quad \text { MolL }^{-1} \\
0.05 \times 10^{-3}\end{array}$ & $\begin{array}{l}K \\
6 \times 10^{-3}\end{array}$ & $\begin{array}{l}K \\
1 \times 10^{-3}\end{array}$ \\
\hline $\begin{array}{l}1 \mathrm{molL}^{-1} \mathrm{KNO}_{3} \\
1 \mathrm{molL}^{-1} \mathrm{Ca}\left(\mathrm{NO}_{3}\right)_{2} \\
1 \mathrm{molL}^{-1} \mathrm{MgSO}_{4} \\
1 \mathrm{molL}^{-1} \mathrm{KH}_{2} \mathrm{PO}_{4} \\
0.1 \mathrm{molL}^{-1} \mathrm{KH}_{2} \mathrm{PO}_{4} \\
1 \mathrm{molL}^{-1} \mathrm{KCl} \\
1 \mathrm{molL}^{-1} \mathrm{NH}_{4} \mathrm{H}_{2} \mathrm{PO}_{4} \\
1 \mathrm{molL}^{-1} \mathrm{FeCl}_{3} \cdot 6 \mathrm{H}_{2} \mathrm{O} \\
\text { Trace element }\end{array}$ & $\begin{array}{l}5(30 \mathrm{ml}) \\
5(30 \mathrm{ml}) \\
2(12 \mathrm{ml}) \\
1(6 \mathrm{ml}) \\
\text { Nil } \\
\text { Nil } \\
\text { Nil } \\
1(2 \mathrm{ml}) \\
1(6 \mathrm{ml})\end{array}$ & $\begin{array}{l}5(30 \mathrm{ml}) \\
5(30 \mathrm{ml}) \\
2(12 \mathrm{ml}) \\
\text { Nil } \\
0.5(3 \mathrm{ml}) \\
0.95(5.7 \mathrm{ml}) \\
\text { Nil } \\
1(2 \mathrm{ml}) \\
1(6 \mathrm{ml})\end{array}$ & $\begin{array}{l}5(30 \mathrm{ml}) \\
5(30 \mathrm{ml}) \\
2(12 \mathrm{ml}) \\
1(6 \mathrm{ml}) \\
\text { Nil } \\
\text { Nil } \\
\text { Nil } \\
1(2 \mathrm{ml}) \\
1(6 \mathrm{ml})\end{array}$ & $\begin{array}{l}1(6 \mathrm{ml}) \\
7(42 \mathrm{ml}) \\
2(12 \mathrm{ml}) \\
\text { Nil } \\
\text { Nil } \\
\text { Nil } \\
1(6 \mathrm{ml}) \\
1(2 \mathrm{ml}) \\
1(6 \mathrm{ml})\end{array}$ \\
\hline
\end{tabular}


Table 2. Nutrient solution level of cotton plants grown hydroponically treated to phosphorus and potassium

\begin{tabular}{llllllllll}
\hline & \multicolumn{9}{c}{ Nutrient solution level (cm) } \\
& \multicolumn{9}{c}{ Days after transplanting } \\
Treatments & 21 & 46 & 57 & 72 & 83 & 91 & 104 & 120 & 148 \\
\hline Low P & $20.04 \mathrm{a}$ & $19.00 \mathrm{a}$ & $19.73 \mathrm{a}$ & $19.34 \mathrm{a}$ & $20.34 \mathrm{a}$ & $19.40 \mathrm{a}$ & $18.63 \mathrm{a}$ & $18.18 \mathrm{a}$ & $18.38 \mathrm{a}$ \\
Low K & $19.79 \mathrm{~b}$ & $16.95 \mathrm{~b}$ & $17.37 \mathrm{~b}$ & $17.25 \mathrm{~b}$ & $16.44 \mathrm{~b}$ & $16.93 \mathrm{~b}$ & $16.43 \mathrm{~b}$ & $15.45 \mathrm{~b}$ & $16.83 \mathrm{~b}$ \\
High PK & $19.84 \mathrm{~b}$ & $17.28 \mathrm{~b}$ & $16.93 \mathrm{~b}$ & $15.29 \mathrm{c}$ & $15.06 \mathrm{~b}$ & $16.00 \mathrm{c}$ & $14.60 \mathrm{c}$ & $12.56 \mathrm{c}$ & $15.81 \mathrm{~b}$ \\
SE & 0.087 & 0.244 & 0.282 & 0.652 & 0.773 & 0.339 & 0.520 & 1.10 & 0.69 \\
\hline
\end{tabular}

SE-Standard Error, P-Phosphorus, K-Potassium. Means within columns followed by the same letter are not significantly different at $\mathrm{P}=0.05$ according to Duncan's multiple range test.

Table 3. Residual phosphorus nutrient level in the hydroponics at the end of every nutrient change planted with cotton plants

\begin{tabular}{llllllllllll}
\hline \multicolumn{1}{c}{ Phosphorus $\left(\mathrm{mgpot}^{-1}\right)$} \\
Treatments & 21 & 46 & 57 & 72 & 83 & 91 & 104 & 120 & 148 \\
\hline Low P & $0.746 \mathrm{a}$ & $0.863 \mathrm{~b}$ & $1.49 \mathrm{c}$ & $0.396 \mathrm{c}$ & $0.449 \mathrm{c}$ & $0.765 \mathrm{c}$ & $0.563 \mathrm{c}$ & $0.705 \mathrm{c}$ & $0.458 \mathrm{c}$ \\
Low K & $0.801 \mathrm{a}$ & $14.67 \mathrm{a}$ & $14.53 \mathrm{a}$ & $16.40 \mathrm{a}$ & $11.72 \mathrm{a}$ & $12.15 \mathrm{a}$ & $12.97 \mathrm{a}$ & $11.21 \mathrm{a}$ & $15.48 \mathrm{a}$ \\
High PK & $0.775 \mathrm{a}$ & $0.548 \mathrm{~b}$ & $4.93 \mathrm{~b}$ & $5.44 \mathrm{~b}$ & $4.65 \mathrm{~b}$ & $9.76 \mathrm{~b}$ & $5.56 \mathrm{~b}$ & $3.84 \mathrm{~b}$ & $3.58 \mathrm{~b}$ \\
SE & 0.083 & 0.697 & 0.541 & 0.482 & 0.375 & 0.697 & 0.946 & 0.704 & 0.509 \\
\hline
\end{tabular}

SE-Standard Error, P-Phosphorus, K-Potassium. Means within columns followed by the same letter are not significantly different at $\mathrm{P}=0.05$ according to Duncan's multiple range test.

Table 4. Residual level of Potassium nutrient in the hydroponics at the end of every nutrient change grown with cotton plants

Potassium (mgpot $\left.{ }^{-1}\right)$

Days after transplanting

\begin{tabular}{llllllllll} 
Treatments & 21 & 46 & 57 & 72 & 83 & 91 & 104 & 120 & 148 \\
\hline Low P & $291.52 \mathrm{a}$ & $274.19 \mathrm{~b}$ & $214.85 \mathrm{~b}$ & $256.88 \mathrm{~b}$ & $260.95 \mathrm{~b}$ & $270.18 \mathrm{~b}$ & $270.52 \mathrm{~b}$ & $277.49 \mathrm{~b}$ & $270.30 \mathrm{~b}$ \\
Low K & $37.37 \mathrm{c}$ & $29.49 \mathrm{c}$ & $38.27 \mathrm{c}$ & $32.46 \mathrm{c}$ & $35.39 \mathrm{c}$ & $39.68 \mathrm{c}$ & $40.11 \mathrm{c}$ & $45.61 \mathrm{c}$ & $47.49 \mathrm{c}$ \\
High PK & $261.77 \mathrm{~b}$ & $283.91 \mathrm{a}$ & $249.82 \mathrm{a}$ & $304.38 \mathrm{a}$ & $313.88 \mathrm{a}$ & $323.99 \mathrm{a}$ & $338.81 \mathrm{a}$ & $339.22 \mathrm{a}$ & $302.50 \mathrm{a}$ \\
SE & 10.06 & 2.57 & 2.86 & 7.86 & 5.93 & 6.13 & 5.56 & 9.27 & 10.57
\end{tabular}

SE-Standard Error, P-Phosphorus, K-Potassium Means within columns followed by the same letter are not significantly different at $\mathrm{P}=0.05$ according to Duncan's multiple range test. 
Table 5. Nutrient solution level as influenced by hormones grown hydroponically in high PK nutrients level

\begin{tabular}{lllll}
\hline \multicolumn{5}{c}{$\begin{array}{c}\text { Nutrient solution level (cm) } \\
\text { Days After Transplanting (DAT) }\end{array}$} \\
Treatment levels & 43 & 74 & 80 & 90 \\
\hline Control & $18.78 \mathrm{a}$ & $15.90 \mathrm{ab}$ & $18.42 \mathrm{~b}$ & $12.50 \mathrm{ab}$ \\
$\mathrm{IAA}$ & $18.43 \mathrm{a}$ & $15.94 \mathrm{ab}$ & $18.17 \mathrm{~b}$ & $14.32 \mathrm{ab}$ \\
$\mathrm{GA}_{3}$ & $18.57 \mathrm{a}$ & $15.49 \mathrm{ab}$ & $18.25 \mathrm{~b}$ & $13.42 \mathrm{ab}$ \\
$\mathrm{Z}$ & $18.50 \mathrm{a}$ & $14.63 \mathrm{~b}$ & $18.18 \mathrm{~b}$ & $13.17 \mathrm{ab}$ \\
$\mathrm{IAA} \times \mathrm{GA}_{3} \times \mathrm{Z}$ & $17.55 \mathrm{~b}$ & $15.41 \mathrm{ab}$ & $19.42 \mathrm{a}$ & $16.00 \mathrm{a}$ \\
$2 \mathrm{IAA} \times \mathrm{GA}_{3} \times \mathrm{Z}$ & $18.24 \mathrm{a}$ & $16.96 \mathrm{a}$ & $19.90 \mathrm{a}$ & $15.15 \mathrm{ab}$ \\
IAA x $2 \mathrm{GA}_{3} \times \mathrm{Z}$ & $18.48 \mathrm{a}$ & $15.99 \mathrm{ab}$ & $19.03 \mathrm{ab}$ & $14.47 \mathrm{ab}$ \\
IAA x GA & $18.14 \mathrm{a}$ & $14.53 \mathrm{~b}$ & $18.23 \mathrm{~b}$ & $11.47 \mathrm{~b}$ \\
$2 \mathrm{IAA} \times 2 \mathrm{GA}_{3} \times 2 \mathrm{Z}$ & $18.38 \mathrm{a}$ & $14.93 \mathrm{~b}$ & $18.42 \mathrm{~b}$ & $14.33 \mathrm{ab}$ \\
$\mathrm{SE}$ & 0.296 & 0.830 & 0.432 & 1.71 \\
\hline
\end{tabular}

SE- Standard Error. IAA-Indole -3-acetic acid, $\mathrm{GA}_{3}$-Gibberellic acid, Z-Zeatin. Means within columns followed by the same letter are not significantly different at $\mathrm{P}=0.05$ according to Duncan's multiple range test.

Table 6. Residual phosphorus nutrient solution analysis treated to different hormones concentration grown hydroponically in high level of PK nutrients planted with cotton plants

\begin{tabular}{lllll} 
& \multicolumn{5}{c}{$\begin{array}{c}\text { Phosphorus (mgpot } \\
\text { Days After Transplanting (DAT) }\end{array}$} \\
Treatment levels & 43 & 74 & 80 & 90 \\
\hline Control & $1.35 \mathrm{a}$ & $0.988 \mathrm{ab}$ & $2.70 \mathrm{ab}$ & $1.52 \mathrm{ab}$ \\
$\mathrm{IAA}$ & $1.22 \mathrm{ab}$ & $1.01 \mathrm{ab}$ & $2.84 \mathrm{ab}$ & $1.89 \mathrm{ab}$ \\
$\mathrm{GA}_{3}$ & $1.22 \mathrm{ab}$ & $1.17 \mathrm{a}$ & $3.12 \mathrm{ab}$ & $2.10 \mathrm{a}$ \\
$\mathrm{Z}$ & $1.21 \mathrm{ab}$ & $0.675 \mathrm{ab}$ & $3.53 \mathrm{a}$ & $1.86 \mathrm{ab}$ \\
$\mathrm{IAA} \times \mathrm{GA}_{3} \times \mathrm{Z}$ & $1.11 \mathrm{~b}$ & $0.498 \mathrm{ab}$ & $2.62 \mathrm{ab}$ & $1.81 \mathrm{ab}$ \\
& & & & \\
$2 \mathrm{IAA} \times \mathrm{GA}_{3} \times \mathrm{Z}$ & $1.18 \mathrm{ab}$ & $0.779 \mathrm{ab}$ & $2.35 \mathrm{~b}$ & $1.29 \mathrm{~b}$ \\
$\mathrm{IAA} \times 2 \mathrm{GA}_{3} \times \mathrm{Z}$ & $1.27 \mathrm{ab}$ & $0.729 \mathrm{ab}$ & $3.11 \mathrm{ab}$ & $1.94 \mathrm{ab}$ \\
$\mathrm{IAA} \times \mathrm{GA}_{3} \times 2 \mathrm{Z}$ & $1.31 \mathrm{ab}$ & $0.453 \mathrm{ab}$ & $3.27 \mathrm{ab}$ & $1.55 \mathrm{ab}$ \\
$2 \mathrm{IAA} \times 2 \mathrm{GA}_{3} \times 2 \mathrm{Z}$ & $1.31 \mathrm{ab}$ & $0.383 \mathrm{~b}$ & $2.68 \mathrm{ab}$ & $1.52 \mathrm{ab}$ \\
$\mathrm{SE}$ & 0.087 & 0.328 & 0.399 & 0.328 \\
\hline
\end{tabular}

SE-Standard Error. IAA-Indole -3-acetic acid,GA $\mathrm{G}_{3}$-Gibberellic acid, Z-Zeatin. Means within columns followed by the same letter are not significantly different at $\mathrm{P}=0.05$ according to Duncan's multiple range test. 
Table 7. Residual potassium nutrient solution analysis treated to different hormones concentration grown hydroponically in high level of PK nutrients planted with cotton plants

\begin{tabular}{|c|c|c|c|c|}
\hline \multirow[b]{3}{*}{ Treatment levels } & \multirow[b]{3}{*}{43} & \multicolumn{3}{|c|}{ Potassium $\left(m g \operatorname{pot}^{-1}\right)$} \\
\hline & & \multicolumn{3}{|c|}{ Days After Transplanting (DAT) } \\
\hline & & 74 & 80 & 90 \\
\hline Control & $136.86 \mathrm{~b}$ & $153.02 \mathrm{ab}$ & $145.15 \mathrm{ab}$ & $163.36 \mathrm{a}$ \\
\hline IAA & $144.53 b$ & $154.33 \mathrm{ab}$ & $133.44 b$ & $190.67 \mathrm{a}$ \\
\hline $\mathrm{GA}_{3}$ & $139.53 b$ & $154.65 \mathrm{ab}$ & $155.55 \mathrm{a}$ & $164.66 \mathrm{a}$ \\
\hline $\mathrm{Z}$ & $137.19 b$ & $152.37 \mathrm{ab}$ & $145.15 \mathrm{ab}$ & $187.42 \mathrm{a}$ \\
\hline IAA $x \mathrm{GA}_{3} \mathrm{x}$ & $160.22 \mathrm{a}$ & $165.41 \mathrm{a}$ & $136.04 \mathrm{ab}$ & $159.45 \mathrm{a}$ \\
\hline $2 \mathrm{IAA} \times \mathrm{GA}_{3} \times \mathrm{Z}$ & $146.20 \mathrm{~b}$ & $149.76 b$ & $137.99 \mathrm{ab}$ & $165.31 \mathrm{a}$ \\
\hline IAA $\times 2 \mathrm{GA}_{3} \times \mathrm{Z}$ & $148.21 b$ & $150.74 b$ & $143.85 \mathrm{ab}$ & $172.46 \mathrm{a}$ \\
\hline IAA $\times \mathrm{GA}_{3} \times 2 \mathrm{Z}$ & $142.87 \mathrm{~b}$ & $157.26 \mathrm{ab}$ & $143.85 \mathrm{ab}$ & $180.91 \mathrm{a}$ \\
\hline $2 \mathrm{IAA} \times 2 \mathrm{GA}_{3} \times 2 \mathrm{Z}$ & $140.86 b$ & $159.54 \mathrm{ab}$ & $149.70 \mathrm{ab}$ & $172.46 \mathrm{a}$ \\
\hline $\mathrm{SE}$ & 5.04 & 6.14 & 8.59 & 27.89 \\
\hline
\end{tabular}

SE-Standard Error, IAA-Indole -3-acetic acid,GA $\mathrm{GA}_{3}$-Gibberellic acid, Z-Zeatin. Means within columns followed by the same letter are not significantly different at $\mathrm{P}=0.05$ according to Duncan's multiple range test.

Table 8. Correlation co- efficient relating low P, low K and high PK plant treatments at 148 days after transplanting to hormones plant treatments at high level of PK at 90 days after transplanting

Growth and yield parameters

Correlation Co-efficient (r) relating low P, low K and high PK to hormones applied

\begin{tabular}{lc}
\hline NUTRIENTS SOLUTION LEVEL & $0.981 \mathrm{~ns}$ \\
P AND K RESIDUAL NUTRIENTS SOLUTION ANALYSIS \\
P & $0.951 \mathrm{~ns}$ \\
$\mathrm{~K}$ & $0.973 \mathrm{~ns}$ \\
\hline
\end{tabular}

Ns: Not significant at $\mathrm{p}<0.005$. P-Phosphorus, K-Potassium 


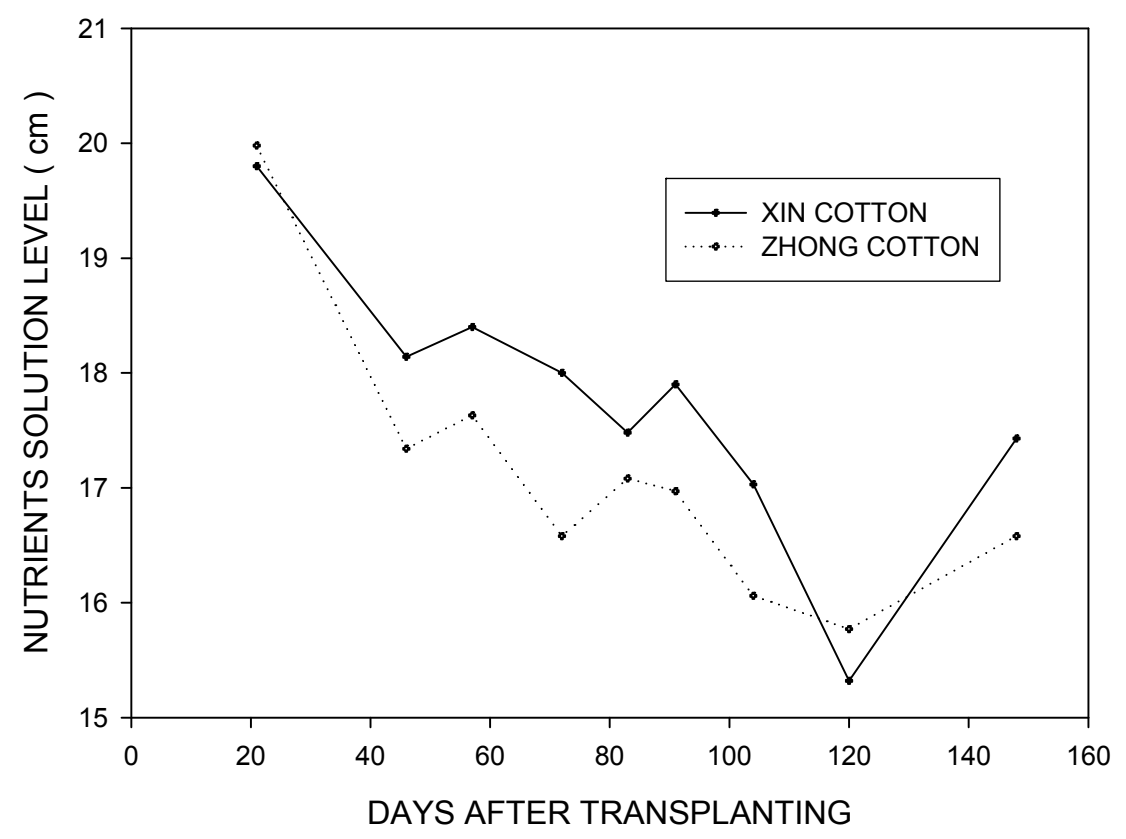

Figure 1. Nutrient solution level of hydroponically grown cotton plant varieties treated to phosphorus and potassium

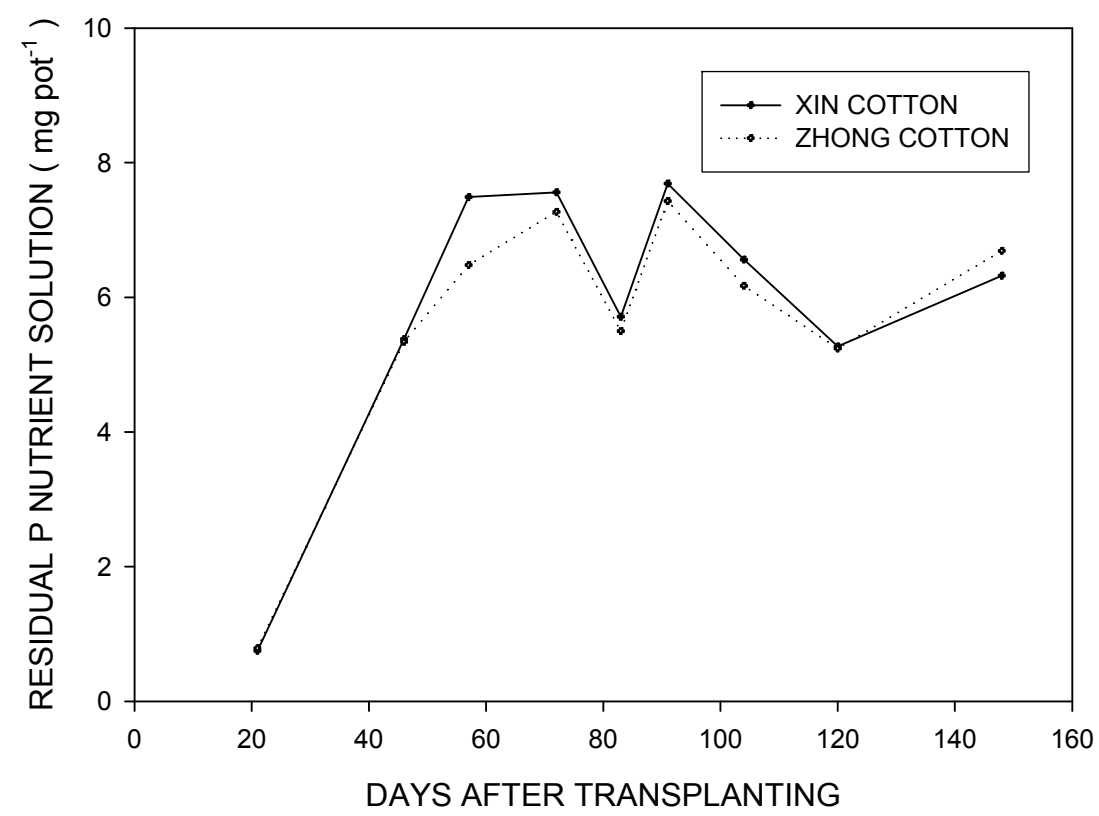

Figure 2. Residual phosphorus nutrient level at the end of every nutrient change grown hydroponically with cotton plant varieties 


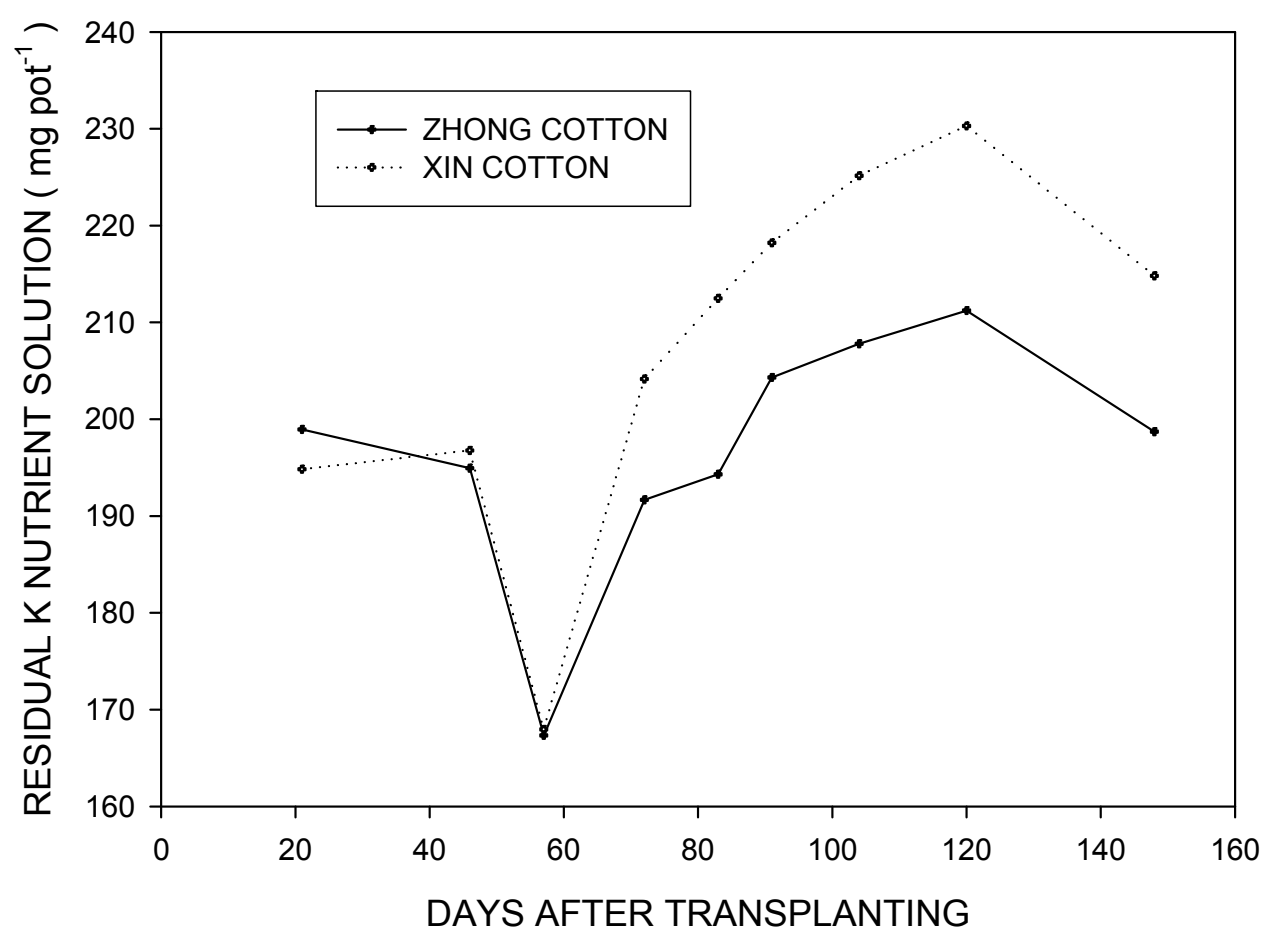

Figure 3. Residual potassium nutrient level at the end of every nutrient change grown hydroponically with cotton plant varieties

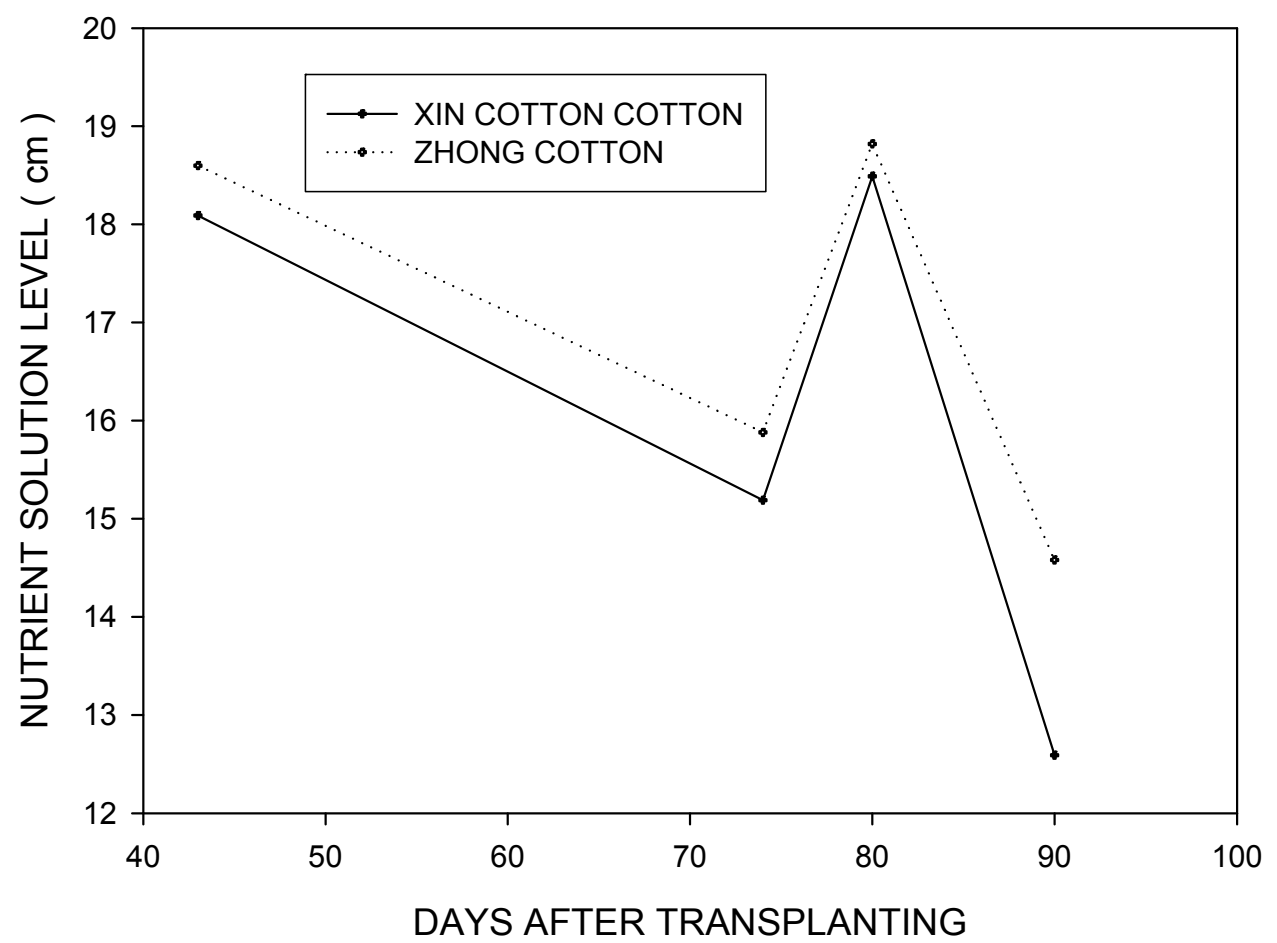

Figure 4. Nutrient solution level as influenced by hormones planted with cotton plant varieties grown hydroponically in high PK nutrients level 


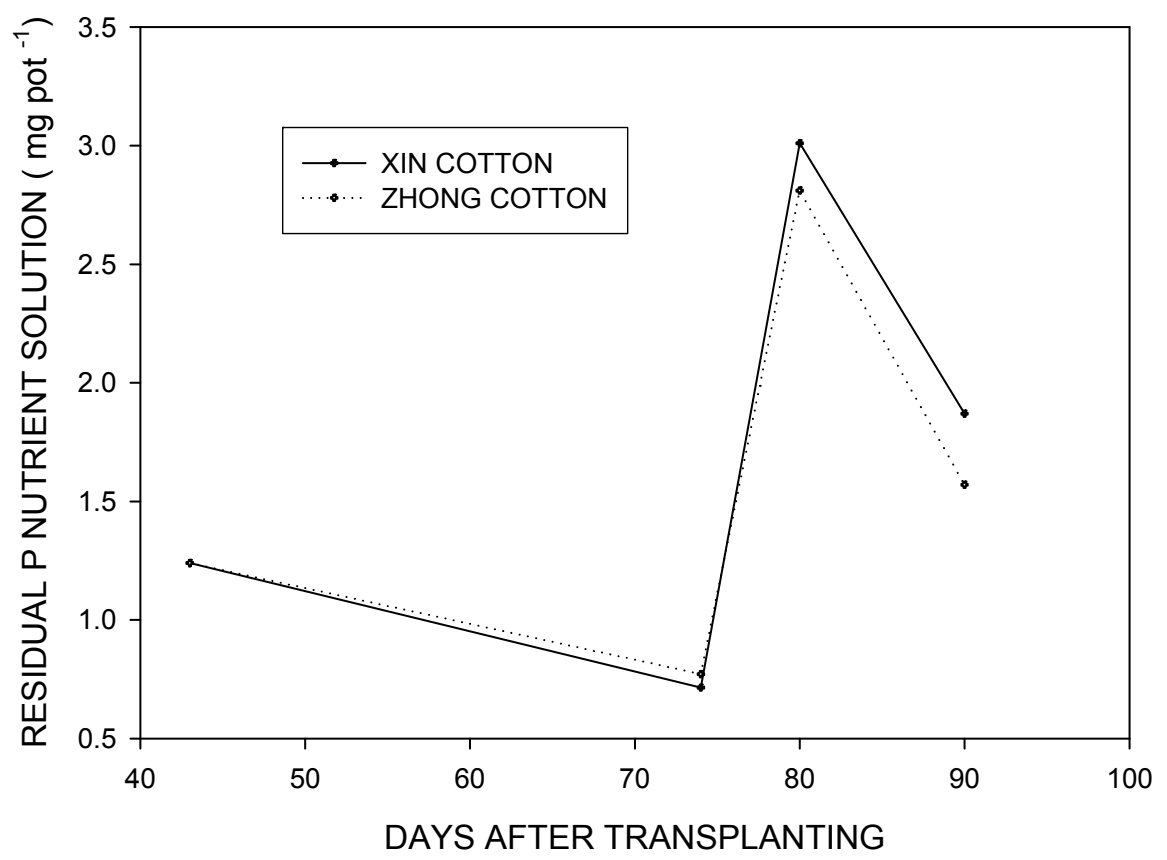

Figure 5. Residual phosphorus nutrient solution analysis treated to different hormones concentration grown hydroponically in high level of PK nutrients planted with cotton varieties

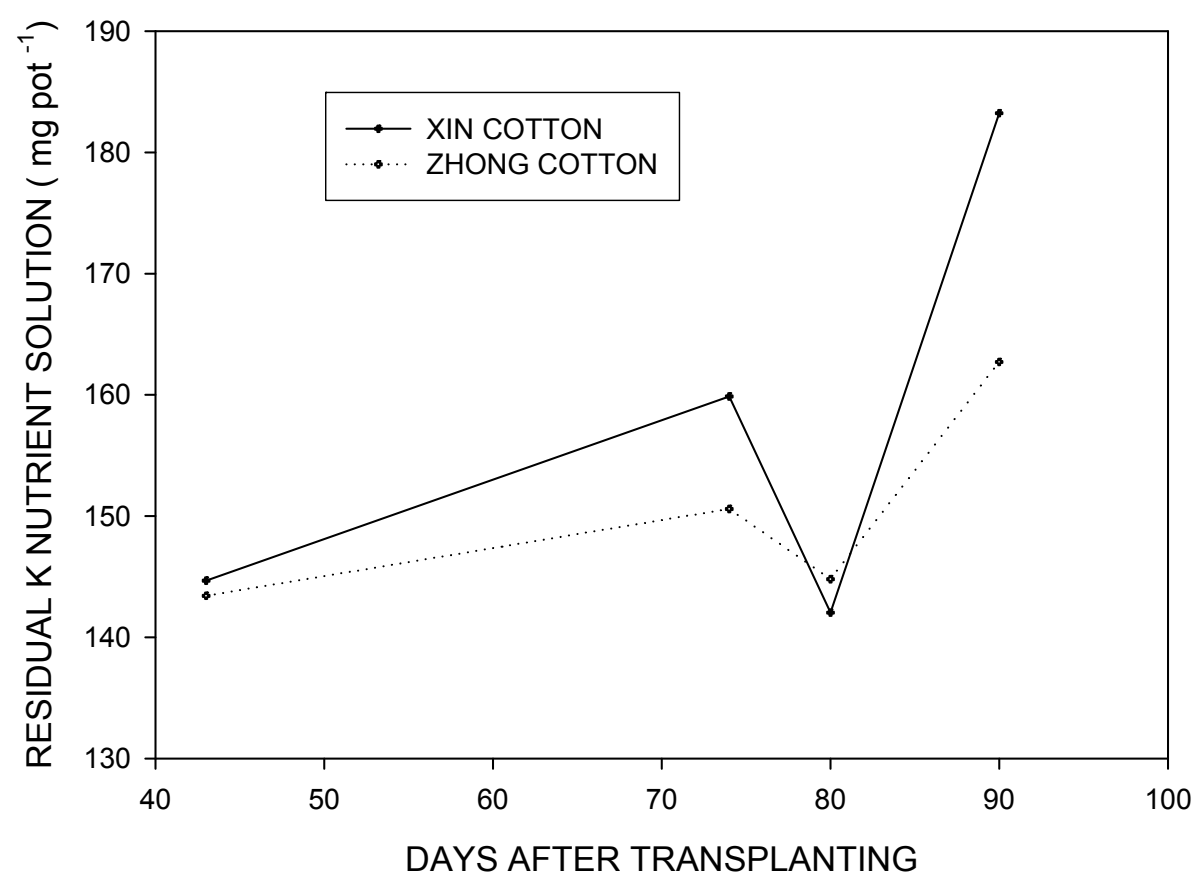

Figure 6. Residual Potassium nutrient solution analysis treated to different hormones concentration grown hydroponically in high level of PK nutrients planted with cotton varieties 